Annals of Pure and Applied Mathematics

Vol. 12, No. 2, 2016, 177-184

ISSN: 2279-087X (P), 2279-0888(online)

Published on 20 November 2016

www.researchmathsci.org

DOI: http://dx. doi.org/10.22457/apam.v12n2a9

Annals of

Pure and Applied Mathematics

\title{
Some Common Fixed Point Theorems in Fuzzy Metric Spaces for Sequence of Self Mapping Using the Property (E.A)
}

\section{Pranjali Sharma $^{1}$ and Shailesh Dhar Diwan ${ }^{2}$}

${ }^{1}$ Department of Mathematics, Shri Shankaracharya Ins. of Prof. Mgmt. and Tech. Raipur (C.G.), India. E-mail: p.sharma@ @ssipmt.com

${ }^{2}$ Department of Mathematics, Govt. Engineering College, Raipur (C.G.), India

E-mail: sdd11@ rediffmail.com

Received 25 October 2016; accepted 9 November 2016

Abstract. In this paper, we establish some common fixed point theorems in fuzzy metric spaces for sequence of self mappings using implicit relation and the property (E.A). Our results extend, generalize and improve several results of metric spaces and menger spaces to fuzzy metric spaces.

Keywords: Fuzzy metric space, t-norm, weakly commuting mappings, (E. A) property, implicit relation

AMS Mathematics Subject Classification (2010): 54H25, 47H10

\section{Introduction}

The idea of fuzzy set was first introduced by Iranian mathematician Zadeh [18]. Fuzzy set is specifically designed to mathematically represent uncertainty and vagueness. Fuzzy set is defined by a membership function which assigns each object to a grade of membership between zero and one. Adak et al. [1] and Pradhan and Pal [14] have done remarkable work on fuzzy set theory. Kramosil and Michalek [10] applied the concept of fuzziness to the classical metric space and compare the fuzzy metric space with probabilistic metric space, the generalization of metric space. George and Veeramani [4] modified the concept of fuzzy metric space by imposing some stronger conditions using continuous t-norm and defined the hausdorff topology of fuzzy metric spaces. Gregori and Sapena [6] defined the concepts of convergent sequence, Cauchy sequence, completeness and compactness in sense of fuzzy metric space. Grabiec [5] introduced the fuzzy version of Banach contraction principle.

Jungck [7] introduced commuting mappings in metric space. Sessa [16] generalized commuting mappings in metric space as weakly commuting mappings. Pant [13] introduced R weak commutativity in metric space. Vasuki (2010) defined R weak commutativity in fuzzy metric space. Jungck [8] enlarged the class of noncommuting mappings by compatible mappings. Also the concept of compatible mappings was further improved by Jungck et al. [9] with the notion of weakly compatible mappings which 
Pranjali Sharma and Shailesh Dhar Diwan

merely commute at coincidence points. Mishra et al. [12] defined compatible mappings in fuzzy metric spaces and proved some common fixed point theorems.

Aamri and El Moutawakil [2] defined the (E.A) property for self mappings whose class contains the class of noncompatible as well as compatible mappings. Common property (E.A) is introduced by Ali et al. [3]. It is observed that (E.A) property and common property (E.A) require the closedness of the subspaces for the existence of fixed point. Mihet [11] defined (E.A) property in fuzzy metric spaces.

In this paper, we prove some common fixed point theorems in fuzzy metric spaces using implicit relation and the common property (E. A).

\section{Preliminaries}

Definition 2.1. (Schweizer B. and Sclar A., 1986) A binary operation

$*:[0,1] \times[0,1] \rightarrow[0,1]$ is called continuous t-norm if it satisfies the following conditions:

1) $*$ is commutative and associative;

2) * is continuous;

3) $\mathrm{a} * 1=\mathrm{a}$, for all a $\in[0,1]$;

4) $\mathrm{a} * \mathrm{~b} \leq \mathrm{c} * \mathrm{~d}$ whenever $\mathrm{a} \leq \mathrm{c}$ and $\mathrm{b} \leq \mathrm{d}$, for all $\mathrm{a}, \mathrm{b}, \mathrm{c}, \mathrm{d} \in[0,1]$.

Remark 2.2. (Schweizer B. and Sclar A., 1986) The concept of t-norm can be considered as fuzzy union.

Definition 2.3. (George A. and Veeramani P., 1994) The 3-tuple (X, M, *) is said to be a fuzzy metric space (FMS) if, $\mathrm{X}$ is a non empty set, $*$ is a continuous $\mathrm{t}$-norm, $\mathrm{M}$ is a fuzzy set on $\mathrm{X} \times \mathrm{X} \times(0, \infty)$ satisfying the following conditions:

1) $\mathrm{M}(\mathrm{x}, \mathrm{y}, \mathrm{t})>0$

2) $M(x, y, t)=1$ if and only if $x=y$;

3) $M(x, y, t)=M(y, x, t)$;

4) $\mathrm{M}(\mathrm{x}, \mathrm{y}, \mathrm{t}) * \mathrm{M}(\mathrm{y}, \mathrm{z}, \mathrm{s}) \leq \mathrm{M}(\mathrm{x}, \mathrm{z}, \mathrm{t}+\mathrm{s})$;

$\mathrm{M}(\mathrm{x}, \mathrm{y}, \cdot):(0, \infty) \rightarrow[0,1]$ is continuous, for all $\mathrm{x}, \mathrm{y}, \mathrm{z} \in \mathrm{X}$ and $\mathrm{s}, \mathrm{t}>0$.

$\mathrm{M}(\mathrm{x}, \mathrm{y}, \mathrm{t})$ is considered as the degree of nearness of $\mathrm{x}$ and $\mathrm{y}$ with respect to $t$.

Example 2.4. (George A. and Veeramani P., 1994)

Let $(X, d)$ be a metric space $a * b=\min \{a, b\}$ and $\forall x, y \in X$ and $t>0$.

then $(\mathrm{X}, \mathrm{M}, *)$ is a Fuzzy metric space.

$$
\mathrm{M}_{\mathrm{d}}(\mathrm{x}, \mathrm{y}, \mathrm{t})=\frac{t}{t+d(x, y)}
$$

Definition 2.5. (Gregori V. and Sapena A., 2002)

I. A sequence $\left\{x_{n}\right\}$ is said to convergent to $x$ in $X$, if and only if $\lim _{n \rightarrow \infty} M\left(x_{n}, x, t\right)$ $=1$ for all $\mathrm{t}>0$.

II. A sequence $\left\{x_{n}\right\}$ is said to $M$ cauchy, if and only if for each $\varepsilon \in(0,1), \mathrm{t}>0$, there exist $\mathrm{n}_{0} \in N$ such that $\lim _{\mathrm{n} \rightarrow \infty} \mathrm{M}\left(\mathrm{x}_{\mathrm{m}}, \mathrm{x}_{\mathrm{n}}, \mathrm{t}\right)>1-$ $\varepsilon$ for any $\mathrm{m}, \mathrm{n} \geq \mathrm{n}_{0}$ for all $\mathrm{t}>0$. 
Some Common Fixed Point Theorems in Fuzzy Metric Spaces for Sequence of Self Mapping Using the Property (E.A)

III. The fuzzy metric space $\mathrm{M}(\mathrm{x}, \mathrm{y}, \mathrm{t})$ is called M-complete if every M-cauchy sequence is convergent.

Definition 2.6. (Vasuki R., 1999) Two self mappings $f$ and $g$ of a fuzzy metric space (X, $\mathrm{M}, *)$ are said to be weakly commuting if,

$M($ fgx, gfx, $t) \geq M(f x, g x t)$, for all $x \in X, t>0$.

Definition 2.7. (Vasuki R., 1999) Two self mappings $f$ and $g$ of a fuzzy metric space (X, $\mathrm{M}, *)$ are said to be $\mathrm{R}$ weakly commuting if,

$$
\mathrm{M}(\mathrm{fgx}, \mathrm{gfx}, t) \geq \mathrm{M}\left(\mathrm{fx}, \mathrm{gx}, \frac{t}{R}\right) \text {, for all } \mathrm{x} \in \mathrm{X}, \mathrm{t}>0 .
$$

Definition 2.8. (Mihet D., 2010) Two self mappings $f$ and $g$ of a fuzzy metric space (X, $\mathrm{M}, *)$ are said to satisfy the (E.A) property if there exist a sequence $\left\{\mathrm{x}_{\mathrm{n}}\right\}$ in $\mathrm{X}$ such that for all $\mathrm{t}>0$,

$$
\lim _{n \rightarrow \infty} M\left(f x_{n}, g x_{n}, t\right)=1 \text {. }
$$

Definition 2.9. (Ali J. et al., 2010) Two pairs (A, S) and (B, T) of self mappings of a fuzzy metric space $(\mathrm{X}, \mathrm{M}, *)$ are said to satisfy the (E.A) property if there exist two sequences $\left\{\mathrm{x}_{\mathrm{n}}\right\}$ and $\left\{\mathrm{y}_{\mathrm{n}}\right\}$ in $\mathrm{X}$ such that for all $\mathrm{t}>0$,

$$
\lim _{n \rightarrow \infty} A x_{n}=\lim _{n \rightarrow \infty} S x_{n}=\lim _{n \rightarrow \infty} B y_{n}=\lim _{n \rightarrow \infty} T y_{n}=z \text {, for some } \mathrm{z} \text { in X. }
$$

\section{Main results}

Definition 3.1. (Implicit relation) Let $\Phi$ be the class of all real valued, non-decreasing and continuous functions, $\phi:\left(R^{+}\right)^{4} \rightarrow R$, satisfying the following condition:

$\phi(x, y, x, y) \geq 0$ or $\phi(x, y, y, x) \geq 0$ or $(x, x, y, y) \geq 0$ implies $x \geq y$, for all $x, y \geq 0$;

Theorem 3.2. Let A, B and $\left\langle F_{i}>\right.$ where $i \square$ Nu $\{0\}$, be self-maps of fuzzy metric space $(\mathrm{X}, \mathrm{M}, *)$, satisfying the following conditions,

I. $\quad \mathrm{F}_{\mathrm{i}} \subseteq B$ and $\mathrm{F}_{0} \subseteq \mathrm{A}$;

II. $\phi\left(M\left(F_{i} x, F_{0} y, k t\right), M(A x, B y, t), M\left(F_{i} x, A x, t\right), M\left(F_{0} y, B y, k t\right)\right) \geq 0$;

III. The pairs $\left(F_{i}, \mathrm{~A}\right)$ and $\left(F_{0}, \mathrm{~B}\right)$ share the common property (E.A.);

IV. The pairs $\left(F_{i}, \mathrm{~A}\right)$ and $\left(F_{0}, \mathrm{~B}\right)$ are R-weakly commuting,

for all $\mathrm{x}, \mathrm{y} \in \mathrm{X}, \mathrm{t}>0, \mathrm{k} \in(0,1)$. If range of one of $\mathrm{A}$ and $\mathrm{B}$ is closed subspace of $\mathrm{X}$, then $<\mathrm{F}_{\mathrm{i}}>$ where $\mathrm{i} \square \mathrm{N} \cup\{0\}, \mathrm{A}$ and $\mathrm{B}$ have a unique common fixed point.

Proof: Since The pairs $\left(F_{i}, \mathrm{~A}\right)$ and $\left(F_{0}, \mathrm{~B}\right)$ share the common property (E.A.), there exist two sequences $\left\{\mathrm{x}_{\mathrm{n}}\right\}$ and $\left\{\mathrm{y}_{\mathrm{n}}\right\}$ such that,

$$
\lim _{n \rightarrow \infty} F_{0} \mathrm{x}_{\mathrm{n}}=\lim _{n \rightarrow \infty} B \mathrm{x}_{\mathrm{n}}=\lim _{n \rightarrow \infty} F_{i} \mathrm{y}_{\mathrm{n}}=\lim _{n \rightarrow \infty} A \mathrm{y}_{\mathrm{n}}=\mathrm{z}
$$

Suppose that $\mathrm{A}(\mathrm{X})$ is a closed subspace of $\mathrm{X}$, then there exists some $\mathrm{u} \square \mathrm{X}$ such that $\mathrm{z}=$ Au.

Now we show that $\mathrm{F}_{\mathrm{i}} \mathrm{u}=\mathrm{z}$. using condition II with $\mathrm{x}=\mathrm{u}$ and $\mathrm{y}=\mathrm{x}_{\mathrm{n}}$.

Taking limit as $\mathrm{n} \rightarrow \infty$

$$
\phi\left(M\left(F_{i} u, F_{0} \mathrm{x}_{\mathrm{n}}, k t\right), M\left(A u, B \mathrm{x}_{\mathrm{n}}, t\right), M\left(F_{i} u, A u, t\right), M\left(F_{0} \mathrm{x}_{\mathrm{n}}, B \mathrm{x}_{\mathrm{n}}, k t\right)\right) \geq 0
$$

$$
\begin{gathered}
\phi\left(M\left(F_{i} u, z, k t\right), M(z, z, t), M\left(F_{i} u, A u, t\right), M(z, z, k t)\right) \geq 0 \\
\phi\left(M\left(F_{i} u, z, k t\right), 1, M\left(F_{i} u, A u, t\right), 1\right) \geq 0
\end{gathered}
$$


Pranjali Sharma and Shailesh Dhar Diwan

Since $\phi$ is non decreasing therefore,

From the definition 3.1

$$
\phi\left(M\left(F_{i} u, z, t\right), 1, M\left(F_{i} u, A u, t\right), 1\right) \geq 0
$$

Therefore, $\mathrm{F}_{\mathrm{i}} \mathrm{u}=\mathrm{z}=\mathrm{Au}$.

$$
M\left(F_{i} u, z, t\right) \geq 1
$$

Since $\mathrm{F}_{\mathrm{i}} \subseteq B$, there exists some $\mathrm{v} \in \mathrm{X}$, such that $\mathrm{F}_{\mathrm{i}} \mathrm{u}=\mathrm{z}=\mathrm{Bv}$.

Now we show that $\mathrm{F}_{0} \mathrm{v}=\mathrm{z}$. using condition II with $\mathrm{y}=\mathrm{v}$ and $\mathrm{x}=\mathrm{y}_{\mathrm{n}}$.

Taking limit as $\mathrm{n} \rightarrow \infty$

$$
\phi\left(M\left(F_{i} y_{n}, F_{0} v, k t\right), M\left(A y_{n}, B v, t\right), M\left(F_{i} y_{n}, A y_{n}, t\right), M\left(F_{0} v, B v, k t\right)\right) \geq 0
$$

From the definition 3.1

$$
\begin{gathered}
\phi\left(M\left(z, F_{0} v, k t\right), M(z, z, t), M(z, z, t), M\left(F_{0} v, z, k t\right)\right) \geq 0 \\
\phi\left(M\left(z, F_{0} v, k t\right), 1,1, M\left(F_{0} v, z, k t\right)\right) \geq 0
\end{gathered}
$$

Therefore, $F_{0} v=z=B v$,

$$
M\left(F_{0} v, z, k t\right) \geq 1
$$

Hence, $\mathrm{F}_{\mathrm{i}} \mathrm{u}=\mathrm{Au}=F_{0} v=B v=z$.

Since $\mathrm{F}_{\mathrm{i}}$ and $\mathrm{A}$ are pointwise R-weakly commutting, there exists $\mathrm{R}>0$ such that,

$\mathrm{M}\left(\mathrm{F}_{\mathrm{i}} \mathrm{Au}, \mathrm{AF}_{\mathrm{i}} \mathrm{u}, \mathrm{t}\right) \geq \mathrm{M}\left(\mathrm{F}_{i} \mathrm{u}, \mathrm{Au}, \frac{\mathrm{t}}{\mathrm{R}}\right)=1$, hence $\mathrm{F}_{\mathrm{i}} \mathrm{Au}=\mathrm{AF}_{\mathrm{i}} \mathrm{u}=\mathrm{F}_{\mathrm{i}} \mathrm{F}_{\mathrm{i}} \mathrm{u}=\mathrm{AAu}$.

Similarily $\mathrm{F}_{0}$ and $\mathrm{B}$ are pointwise $\mathrm{R}$-weakly commutting, there exists $\mathrm{R}>0$ such that,

$\mathrm{M}\left(\mathrm{F}_{0} \mathrm{Bv}, \mathrm{BF}_{0} \mathrm{v}, \mathrm{t}\right) \geq \mathrm{M}\left(F_{0} \mathrm{v}, \mathrm{Bv}, \frac{\mathrm{t}}{\mathrm{R}}\right)=1$ hence $\mathrm{F}_{0} \mathrm{Bv}=\mathrm{BF}_{0} \mathrm{v}=\mathrm{F}_{0} \mathrm{~F}_{0} \mathrm{v}=\mathrm{BBv}$.

using condition II with $\mathrm{y}=\mathrm{v}$ and $\mathrm{x}=\mathrm{F}_{\mathrm{i}} \mathrm{u}$,

$$
\begin{aligned}
& \phi\left(M\left(F_{i} F_{i} u, F_{0} v, k t\right), M\left(A F_{i} u, B v, t\right), M\left(F_{i} F_{i} u, A F_{i} u, t\right), M\left(F_{0} v, B v, k t\right)\right) \geq 0 \\
& \phi\left(M\left(F_{i} F_{i} u, F_{i} u, k t\right), M\left(F_{i} F_{i} u, F_{i} u, t\right), 1,1\right) \geq 0
\end{aligned}
$$

Since $\phi$ is non decreasing therefore,

From the definition 3.1,

$$
\phi\left(M\left(F_{i} F_{i} u, F_{i} u, t\right), M\left(F_{i} F_{i} u, F_{i} u, t\right), 1,1\right) \geq 0
$$

It is possible only when, $F_{i} F_{i} u=F_{i} u$

$$
M\left(F_{i} F_{i} u, F_{i} u, t\right) \geq 1
$$

Hence, $F_{i} z=z$

Therefore, $F_{i} z=z=A z$

Therefore $\mathrm{z}$ is a fixed point of $F_{i}$ and A.

Now using condition II with $\mathrm{y}=\mathrm{F}_{0} \mathrm{~V}$ and $\mathrm{x}=\mathrm{u}$,

$$
\begin{gathered}
\phi\left(M\left(F_{i} u, F_{0} F_{0} \mathrm{v}, k t\right), M\left(A u, B F_{0} \mathrm{v}, t\right), M\left(F_{i} u, A u, t\right), M\left(F_{0} F_{0} \mathrm{v}, B F_{0} \mathrm{v}, k t\right)\right) \geq 0 \\
\phi\left(M\left(F_{0} v, F_{0} F_{0} \mathrm{v}, k t\right), M\left(F_{0} v, F_{0} F_{0} \mathrm{v}, t\right), 1,1\right) \geq 0
\end{gathered}
$$

Since $\phi$ is non decreasing therefore,

$$
\phi\left(M\left(F_{0} v, F_{0} F_{0} \mathrm{v}, t\right), M\left(F_{0} v, F_{0} F_{0} \mathrm{v}, t\right), 1,1\right) \geq 0
$$

From the definition 3.1,

It is possible only when, $F_{0} v=F_{0} F_{0} \mathrm{~V}=\mathrm{z}$

$$
M\left(F_{0} v, F_{0} F_{0} \mathrm{v}, t\right) \geq 1
$$

Hence, $F_{0} z=z$

Therefore, $F_{0} z=B z=z$

Therefore $\mathrm{z}$ is a fixed point of $F_{0}$ and $\mathrm{B}$.

This gives, $F_{i} Z=A=F_{0} z=B z=z$.

Hence $\mathrm{z}$ is a common fixed point of $\left\langle\mathrm{F}_{\mathrm{i}}\right\rangle, \mathrm{A}$ and $\mathrm{B}$. 
Some Common Fixed Point Theorems in Fuzzy Metric Spaces for Sequence of Self Mapping Using the Property (E.A)

Now to show that $\mathrm{z}$ is unique common fixed point of $\left\langle\mathrm{F}_{\mathrm{i}}\right\rangle$, where $\mathrm{i} \square \mathrm{N} \cup\{0\}$, A and $\mathrm{B}$. Suppose $z_{1}$ is another common fixed point of $\left\langle F_{i}\right\rangle$, where $i \square N \cup\{0\}, A$ and $B$.

Now using condition II with $\mathrm{y}=\mathrm{z}_{1}$ and $\mathrm{x}=\mathrm{z}$,

$$
\begin{gathered}
\phi\left(M\left(F_{i} z, F_{0} z_{1}, k t\right), M\left(A z, B z_{1}, t\right), M\left(F_{i} z, A z, t\right), M\left(F_{0} z_{1}, B z_{1}, k t\right)\right) \geq 0 \\
\phi\left(M\left(z, z_{1}, k t\right), M\left(z, z_{1}, t\right), 1,1\right) \geq 0
\end{gathered}
$$

Since $\phi$ is non decreasing therefore,

$$
\phi\left(M\left(z, z_{1}, t\right), M\left(z, z_{1}, t\right), 1,1\right) \geq 0
$$

From the definition 3.1,

$$
M\left(z, z_{1}, t\right) \geq 1
$$

It is possible only when, $\mathrm{z}=\mathrm{z}_{1}$

Hence $\mathrm{z}$ is unique common fixed point of $\left\langle\mathrm{F}_{\mathrm{i}}>\right.$ where $\mathrm{i} \square \mathrm{N} \cup\{0\}$, $\mathrm{A}$ and $\mathrm{B}$.

Theorem 3.3. Let A, B, F and $\mathrm{G}$ be self-maps of fuzzy metric space (X, M, *), satisfying the following conditions,

I. $\mathrm{F} \subseteq B$ and $\mathrm{G} \subseteq \mathrm{A}$;

II. $\quad \phi(M(F x, G y, k t), M(A x, B y, t), M(F x, A x, t), M(G y, B y, k t)) \geq 0$;

III. The pairs $(F, \mathrm{~A})$ and $(G, \mathrm{~B})$ share the common property (E.A.);

IV. The pairs $(F, \mathrm{~A})$ and $(G, \mathrm{~B})$ are $\mathrm{R}$-weakly commuting,

for all $x, y \in X, t>0, k \in(0,1)$. If range of one of $A$ and $B$ is closed subspace of $X$, then $\mathrm{F}, \mathrm{G}, \mathrm{A}$ and $\mathrm{B}$ have unique common fixed point.

Proof: Since The pairs $(F, \mathrm{~A})$ and $(G, \mathrm{~B})$ share the common property (E.A.), there exist two sequences $\left\{\mathrm{x}_{\mathrm{n}}\right\}$ and $\left\{\mathrm{y}_{\mathrm{n}}\right\}$ such that,

$$
\lim _{n \rightarrow \infty} G \mathrm{x}_{\mathrm{n}}=\lim _{n \rightarrow \infty} B \mathrm{x}_{\mathrm{n}}=\lim _{n \rightarrow \infty} F \mathrm{y}_{\mathrm{n}}=\lim _{n \rightarrow \infty} A \mathrm{y}_{\mathrm{n}}=\mathrm{z}
$$

Suppose that $\mathrm{A}(\mathrm{X})$ is a closed subspace of $\mathrm{X}$, then there exists some $\mathrm{u} \square \mathrm{X}$ such that $\mathrm{z}=$ $\mathrm{Au}$.

Now we show that $\mathrm{Fu}=\mathrm{z}$. using condition II with $\mathrm{x}=\mathrm{u}$ and $\mathrm{y}=\mathrm{x}_{\mathrm{n}}$.

Taking limit as $\mathrm{n} \rightarrow \infty$

$$
\phi\left(M\left(F u, G \mathrm{x}_{\mathrm{n}}, k t\right), M\left(A u, B \mathrm{x}_{\mathrm{n}}, t\right), M(F u, A u, t), M\left(G \mathrm{x}_{\mathrm{n}}, B \mathrm{x}_{\mathrm{n}}, k t\right)\right) \geq 0
$$

$$
\begin{gathered}
\phi(M(F u, z, k t), M(z, z, t), M(F u, A u, t), M(z, z, k t)) \geq 0 \\
\phi(M(F u, z, k t), 1, M(F u, A u, t), 1) \geq 0
\end{gathered}
$$

Since $\phi$ is non decreasing therefore,

$$
\phi(M(F u, z, t), 1, M(F u, A u, t), 1) \geq 0
$$

From the definition 3.1,

$$
M(F u, z, k t) \geq 1
$$

Therefore $\mathrm{Fu}=\mathrm{z}=\mathrm{Au}$.

Since $\mathrm{F} \subseteq B$, there exists some $\mathrm{v} \in \mathrm{X}$, such that $\mathrm{Fu}=\mathrm{z}=\mathrm{v}$.

Now we show that, $\mathrm{Gv}=\mathrm{z}$. using condition II with $\mathrm{y}=\mathrm{v}$ and $\mathrm{x}=\mathrm{y}_{\mathrm{n}}$.

Taking limit as $\mathrm{n} \rightarrow \infty$

$$
\phi\left(M\left(F y_{n}, G v, k t\right), M\left(A y_{n}, B v, t\right), M\left(F y_{n}, A y_{n}, t\right), M(G v, B v, k t)\right) \geq 0
$$

Since $\phi$ is non decreasing therefore,

$$
\phi(M(z, G v, k t), M(z, z, t), M(z, z, t), M(G v, z, k t)) \geq 0
$$

Therefore, $G v=z=B v$,

$$
M(F v, z, k t) \geq 1
$$

Hence, $\mathrm{Fu}=\mathrm{Au}=G v=B v=z$.

Since $\mathrm{F}$ and $\mathrm{A}$ are pointwise R-weakly commutting, there exists $\mathrm{R}>0$ such that, 
Pranjali Sharma and Shailesh Dhar Diwan

$\mathrm{M}(\mathrm{FAu}, \mathrm{AFu}, \mathrm{t}) \geq \mathrm{M}\left(F \mathrm{u}, \mathrm{Au}, \frac{\mathrm{t}}{\mathrm{R}}\right)=1$ that is, $\mathrm{FAu}=\mathrm{AFu}=\mathrm{FFu}=\mathrm{AAu}$.

Similarily, $\mathrm{G}$ and $\mathrm{B}$ are pointwise R-weakly commutting, there exists $\mathrm{R}>0$ such that,

$\mathrm{M}(\mathrm{GBv}, \mathrm{BGv}, \mathrm{t}) \geq \mathrm{M}\left(\mathrm{Gv}, \mathrm{Bv}, \frac{\mathrm{t}}{\mathrm{R}}\right)=1$ that is, $\mathrm{GBv}=\mathrm{BGv}=\mathrm{GGv}=\mathrm{BBv}$.

using condition II with $\mathrm{y}=\mathrm{v}$ and $\mathrm{x}=\mathrm{F}_{\mathrm{i}} \mathrm{u}$,

$$
\begin{aligned}
& \phi(M(F F u, G v, k t), M(A F u, B v, t), M(F F u, A F u, t), M(G v, B v, k t)) \geq 0 \\
& \phi(M(F F u, F u, k t), M(F F u, F u, t), 1,1) \geq 0
\end{aligned}
$$

Since $\phi$ is non decreasing therefore,

$$
\phi(M(F F u, F u, t), M(F F u, F u, t), 1,1) \geq 0
$$

From the definition 3.1,

It is possible only when, $F F u=F u$

$$
M(F F u, F u, t) \geq 1
$$

Hence, $F Z=Z$

Therefore, $F z=z=A z$

Therefore $\mathrm{z}$ is a fixed point of $F$ and $\mathrm{A}$.

Now using condition II with $\mathrm{y}=\mathrm{Gv}$ and $\mathrm{x}=\mathrm{u}$,

$$
\begin{gathered}
\phi(M(F u, G G \mathrm{v}, k t), M(A u, B G \mathrm{v}, t), M(F u, A u, t), M(G G \mathrm{v}, B G \mathrm{v}, k t)) \geq 0 \\
\phi(M(G G v, G \mathrm{v}, k t), M(G G v, G \mathrm{v}, t), 1,1) \geq 0
\end{gathered}
$$

Since $\phi$ is non decreasing therefore,

From the definition 3.1,

$$
\phi(M(G G v, G \mathrm{v}, t), M(G G v, G \mathrm{v}, t), 1,1) \geq 0
$$

It is possible only when, $G v=G G \mathrm{v}=\mathrm{z}$

$$
M(G G v, G \mathrm{v}, t) \geq 1
$$

Hence, $G z=z$

Therefore, $G z=B z=z$

Therefore $\mathrm{z}$ is a fixed point of $G$ and $\mathrm{B}$.

This gives, $F z=A=G z=B z=z$.

Hence $z$ is a common fixed point of F, G, A and B.

Now to show that $\mathrm{z}$ is unique common fixed point of $\mathrm{F}, \mathrm{G}, \mathrm{A}$ and $\mathrm{B}$.

Suppose $z_{1}$ is another common fixed point of $F, G, A$ and $B$.

Now using condition II with $\mathrm{y}=\mathrm{z}_{1}$ and $\mathrm{x}=\mathrm{z}$,

$$
\begin{gathered}
\phi\left(M\left(F z, G z_{1}, k t\right), M\left(A z, B z_{1}, t\right), M(F z, A z, t), M\left(F z_{1}, B z_{1}, k t\right)\right) \geq 0 \\
\phi\left(M\left(z, z_{1}, k t\right), M\left(z, z_{1}, t\right), 1,1\right) \geq 0
\end{gathered}
$$

Since $\phi$ is non decreasing therefore,

$$
\phi\left(M\left(z, z_{1}, t\right), M\left(z, z_{1}, t\right), 1,1\right) \geq 0
$$

From the definition 3.1,

$$
M\left(z, z_{1}, t\right) \geq 1
$$

It is possible only when, $\mathrm{z}=\mathrm{z}_{1}$.

Hence $\mathrm{z}$ is unique common fixed point of $\mathrm{F}, \mathrm{G}, \mathrm{A}$ and $\mathrm{B}$.

Corollary 3.4. Let A, B and $\left\langle F_{i}>\right.$ where $\mathrm{i} \square \mathrm{Nu}\{0\}$, be self-maps of fuzzy metric space $(\mathrm{X}, \mathrm{M}, *)$, satisfying the following conditions,
I. $\quad \mathrm{F}_{\mathrm{i}} \subseteq B$ and $\mathrm{F}_{0} \subseteq \mathrm{A}$;
II. $\phi\left(M\left(F_{i} x, F_{0} y, k t\right), M(A x, B y, t), M\left(F_{i} x, A x, t\right), M\left(F_{0} y, B y, k t\right)\right) \geq 0$;
III. The pair $\left(F_{0}, \mathrm{~B}\right)$ satisfies property (E.A.);
IV. The pairs $\left(F_{i}, \mathrm{~A}\right)$ and $\left(F_{0}, \mathrm{~B}\right)$ are R-weakly commuting, 
Some Common Fixed Point Theorems in Fuzzy Metric Spaces for Sequence of Self Mapping Using the Property (E.A)

for all $x, y \in X, t>0, k \in(0,1)$. If range of one of $A$ and $B$ is closed subspace of $X$, then $\left\langle\mathrm{F}_{\mathrm{i}}\right\rangle$ where $i \in \mathrm{N} \cup\{0\}$, A and $\mathrm{T}$ have a unique common fixed point.

Proof: Since the pair $\left(F_{0}, B\right)$ share the common property (E.A), there exist a sequence $\left\{\mathrm{x}_{\mathrm{n}}\right\}$ such that,

$\lim _{n \rightarrow \infty} F_{0} \mathrm{x}_{\mathrm{n}}=\lim _{n \rightarrow \infty} B \mathrm{x}_{\mathrm{n}}=\mathrm{z}$, for some $\mathrm{z} \in X$.

Since $F_{0}(X) \subseteq A(X)$, there exists $\left\{\mathrm{y}_{\mathrm{n}}\right\}$ in $\mathrm{X}$ such that, $F_{0} \mathrm{x}_{\mathrm{n}}=\mathrm{Ay}_{\mathrm{n}}$ and $\lim _{n \rightarrow \infty} A \mathrm{y}_{\mathrm{n}}=\mathrm{z}$.

Now we show that, $\lim _{n \rightarrow \infty} F_{i} \mathrm{y}_{\mathrm{n}}=\mathrm{z}$.

Using condition II with $\mathrm{x}=\mathrm{y}_{\mathrm{n}}$ and $\mathrm{y}=\mathrm{x}_{\mathrm{n}}$.

$$
\phi\left(M\left(F_{i} y_{n}, F_{0} x_{n}, k t\right), M\left(A y_{n}, B x_{n}, t\right), M\left(F_{i} y_{n}, A y_{n}, t\right), M\left(F_{0} x_{n}, B x_{n}, k t\right)\right) \geq 0
$$

Taking limit as $\mathrm{n} \rightarrow \infty$

Since $\phi$ is non decreasing therefore,

$$
\begin{gathered}
\phi\left(M\left(F_{i} y_{n}, z, k t\right), M(z, z, t), M\left(F_{i} y_{n}, z, t\right), M(z, z, k t)\right) \geq 0 \\
\phi\left(M\left(F_{i} y_{n}, z, k t\right), 1, M\left(F_{i} y_{n}, z, t\right), 1\right) \geq 0
\end{gathered}
$$

From the definition 3.1,

$$
\phi\left(M\left(F_{i} y_{n}, z, t\right), 1, M\left(F_{i} y_{n}, z, t\right), 1\right) \geq 0
$$

It is possible only when, $\lim _{n \rightarrow \infty} F_{i} \mathrm{y}_{\mathrm{n}}=\mathrm{z}$.

$$
M\left(F_{i} y_{n}, z, t\right) \geq 1
$$

Therefore,

$$
\lim _{n \rightarrow \infty} F_{0} \mathrm{x}_{\mathrm{n}}=\lim _{n \rightarrow \infty} B \mathrm{x}_{\mathrm{n}}=\lim _{n \rightarrow \infty} F_{i} \mathrm{y}_{\mathrm{n}}=\lim _{n \rightarrow \infty} A \mathrm{y}_{\mathrm{n}}=\mathrm{z}
$$

The pairs $\left(F_{i}, \mathrm{~A}\right)$ and $\left(F_{0}, \mathrm{~B}\right)$ share the common property (E.A).

Therefore all the conditions of theorem 3.1 are satisfied hence $<F_{i}>$ where $\mathrm{i} \square \mathrm{Nu}\{0\}$, $\mathrm{A}$ and $\mathrm{B}$ have a unique common fixed point.

Corollary 3.5. Let A and B be self mappings of fuzzy metric space (X, $M, *)$, satisfying the following conditions:

I. $\phi(M(A x, A y, k t), M(B x, B y, t), M(A x, B x, t), M(A y, B y, k t)) \geq 0$;

II. The pair (A, B) satisfies property (E.A.);

III. The pair A and B are R-weakly commuting;

IV. Range of $\mathrm{B}$ is closed subspace of $\mathrm{X}$,

for all $\mathrm{x}, \mathrm{y} \in \mathrm{X}, \mathrm{t}>0, \mathrm{k} \in(0,1)$, then $\mathrm{A}$ and $\mathrm{B}$ have unique common fixed point in $\mathrm{X}$.

Proof: The proof can be obtained by putting $\mathrm{F}_{\mathrm{i}}=\mathrm{F}_{0}=\mathrm{A}$ and $\mathrm{A}=\mathrm{B}$ in theorem 3.1.

Corollary 3.6. Let A and I be self mappings of fuzzy metric space (X, M, * ), satisfying the following conditions,
I. $\quad \phi(M(A x, A y, k t), M(x, y, t), M(A x, x, t), M(A y, y, k t)) \geq 0$;
II. The pair (A, I) satisfies property (E.A.),
for all $\mathrm{x}, \mathrm{y} \in \mathrm{X}, \mathrm{t}>0, \mathrm{k} \in(0,1)$, then $\mathrm{A}$ has unique common fixed point in $\mathrm{X}$.

Proof: The proof can be obtained by putting $\mathrm{F}_{\mathrm{i}}=\mathrm{F}_{0}=\mathrm{A}$ and $\mathrm{A}=\mathrm{B}=\mathrm{I}$ in theorem 3.1.

Example 3.7. Let $(X, M, *)$ be a fuzzy metric space, $X=[1,-1]$ with $\mathrm{M}(\mathrm{x}, \mathrm{y}, \mathrm{t})=\frac{t}{t+|x-y|}$, for all $\mathrm{x}, \mathrm{y} \in \mathrm{X}, \mathrm{a} * b=\min \{a, b\}$ for all $\mathrm{a}, \mathrm{b} \in[0,1], \mathrm{t}>0$, let

$$
\mathrm{F}_{\mathrm{i}} \mathrm{X}=\frac{x}{10 i} \text { for } \mathrm{i} \in \mathrm{N}, \mathrm{F}_{0} \mathrm{x}=0, \mathrm{Ax}=-\mathrm{x}, \mathrm{Bx}=\mathrm{x},\left\langle\mathrm{x}_{\mathrm{n}}>=\frac{1}{n},\left\langle\mathrm{y}_{\mathrm{n}}>=\frac{-1}{n}\right. \text {, }\right.
$$


Pranjali Sharma and Shailesh Dhar Diwan

Since, and $A i(X) \in T(X), A 0(X) \in S(X)$.

$$
\lim _{n \rightarrow \infty} F_{0} \mathrm{x}_{\mathrm{n}}=\lim _{n \rightarrow \infty} B \mathrm{x}_{\mathrm{n}}=\lim _{n \rightarrow \infty} F_{i} \mathrm{y}_{\mathrm{n}}=\lim _{n \rightarrow \infty} A \mathrm{y}_{\mathrm{n}}
$$

Also $\mathrm{M}\left(\mathrm{F}_{\mathrm{i}} \mathrm{Ax}, \mathrm{AF}_{\mathrm{i}} \mathrm{x}, t\right) \geq \mathrm{M}\left(\mathrm{F}_{\mathrm{i}} \mathrm{x}, \mathrm{Ax}, \frac{t}{R}\right), \mathrm{M}\left(\mathrm{F}_{0} \mathrm{Bx}, \mathrm{BF}_{0} \mathrm{x}, t\right) \geq \mathrm{M}\left(\mathrm{F}_{\mathrm{i} x}, \mathrm{Sx}, \frac{t}{R}\right)$ for all $\mathrm{x} \in \mathrm{X}$.

Therefore, $\left(\mathrm{F}_{\mathrm{i}}, \mathrm{A}\right)$ and $\left(\mathrm{F}_{0}, \mathrm{~B}\right)$ are $\mathrm{R}$ weakly commuting.

Let $\phi: R^{+} \rightarrow R$ be defined as,

$$
\phi(a, b, c, d)=a-b
$$

Therefore all the conditions of theorem 3.2 are satisfied and 0 is the common fixed point.

\section{REFERENCES}

1. A.K.Adak, M.Bhowmik and M.Pal, Intuitionistic fuzzy block matrix and its some properties, Annals of Pure and Applied Mathematics, 1(1) (2012) 13-31.

2. M.Aamri M. and D.E.Moutawakil, Some new common fixed point theorems under strict contractive conditions, Journal of Mathematical Analysis and Applications, 270 (2002) 181-188.

3. J.Ali, M.Imdad and D.Bahuguna, Common fixed point theorems in Menger spaces with common property (E.A), Comput. Math. Appl., 60(12) (2010) 3152-3159.

4. V.George and P.Veeramani, On some results in Fuzzy Metric Spaces, Fuzzy Sets and System, 64 (1994) 395-399.

5. M.Grabiec, Fixed points in fuzzy metric spaces, Fuzzy Sets and Systems, 27(1989) 385-389.

6. V.Gregori and A.Sapena, On fixed point theorem in fuzzy metric spaces, Fuzzy Sets and Systems, 125 (2002) 245-252.

7. G.Jungck, Commuting mappings and fixed points, Amer. Math. Monthly, 83(1976) 261-263.

8. G.Jungck, Compatible mappings and common fixed points, Internet. J. Math. Math. Sci., 9 (1986) 771-779.

9. G.Jungck and B.E. Rhoades,Fixed point Theorems for occasionally weakly compatible mappings, Fixed Point Theory, 7 (2006) 286-296.

10. O.Kramosil and J.Michalek, Fuzzy metric and statistical metric spaces, Kybernetika, 11 (1976) 326-334.

11. D.Mihet, Fixed point theorems in fuzzy metric spaces using property (E.A), Nonlinear Anal., 73 (2010) 2184-2188.

12. S.N.Mishra, Common fixed points of compatible mappings in PM spaces, Math. Japon., 36 (1991) 283-289.

13. R.P.Pant, Common fixed points of non commuting mappings, J. Math. Anal. Appl., 188(2) (1994) 436-440.

14. R.Pradhan and M.Pal, Intuitionistic fuzzy linear transformations, Annals of Pure and Applied Mathematics, 1(1) (2012) 57-68.

15. Schweizer and A.Sclar, Statistical metric space, Pacific J. Math., (1960) 314-334.

16. S.Sessa, On a weak commutativity condition in a fixed point considation, Publication of Inst. Mathematics, 32(46) (1986) 149-153.

17. R.Vasuki, Common fixed points for R-weakly commuting maps in fuzzy metric spaces, Indian J. Pure Appl. Math., 30 (1999) 419-423.

18. L.A.Zadeh, Fuzzy sets, Inform and Control, 8 (1965) 338-353. 